Article

\title{
Phylogenetic Analysis of Belgian Small Ruminant Lentiviruses Supports Cross Species Virus Transmission and Identifies New Subtype B5 Strains
}

\author{
Rodolphe Michiels *, Nadjah Radia Adjadj and Nick De Regge \\ Unit of Enzootic, Vector-Borne and Bee Diseases, Sciensano, Groeselenberg 99, 1180 Brussels, Belgium; \\ nadjahradia.adjadj@sciensano.be (N.R.A.); nick.deregge@sciensano.be (N.D.R.) \\ * Correspondence: rodolphe.michiels@sciensano.be; Tel.: +32-2-379-05-61; Fax: +32-2-379-06-70
}

Received: 7 January 2020; Accepted: 26 February 2020; Published: 3 March 2020

\begin{abstract}
Small ruminant lentiviruses (SRLV) are a group of highly divergent viruses responsible for global and fatal infections in sheep and goats. Since the current phylogenetic classification of these viruses was proposed in 2004, it nowadays consists out of 5 genotypes and 28 subtypes. In support of our national SRLV control program, we performed the genetic characterization of SRLV strains circulating in the Belgian sheep and goat population. Fourteen sheep and 9 goat strains were sequenced in the gag-pol and pol regions using the method described by Shah. Most SRLV strains from sheep and goats belonged to prototype A1 and B1 subtypes, respectively. We, however, also found indications for cross-species transmission of SRLV strains between sheep and goats and vice versa, and identified a new subtype designated as B5. An in-depth analysis of the current SRLV phylogeny revealed that many subtypes have been defined over the years based on limited sequence information. To keep phylogeny as a useful tool, we advocate to apply more rigorous sequencing standards to ensure the correct classification of current and new emerging strains. The genetic characterization of Belgian SRLV strains will help in the development of appropriate diagnostic tools to assist the national control program.
\end{abstract}

Keywords: Maedi-Visna virus; caprine arthritis encephalitis virus; small ruminant lentivirus; phylogeny; Belgium; cross-species transmission; subtype B5

\section{Introduction}

Maedi-Visna virus (MVV) and caprine arthritis encephalitis virus (CAEV), also referred to as small ruminant lentiviruses (SRLV), are two related retroviruses infecting sheep and goats [1,2]. They are both responsible for a persistent and lifelong infection by targeting the monocytes of the host and the stem cells located in the bone marrow [2]. SRLV induce a multisystemic disease with progressive inflammatory lesions in the mammary gland, lungs, joints, and the brain. Symptoms such as pneumonia, arthritis, and mastitis are commonly observed in one third of the infected animals $[3,4]$. SRLV are mainly transmitted vertically to newborns via the ingestion of infected milk and colostrum but also horizontal transmission can occur at any age via the inhalation of viral particles between animals housed in close contact $[5,6]$. The incidence of these infections causes considerable economical losses in animal production and no therapy or vaccine is currently available [7].

Initially, MVV in sheep and CAEV in goats were described to be strictly host specific. Phylogenetic studies have however revealed that cross-species transmission has occurred in the past. For this reason, both viruses are nowadays referred to as one group called SRLVs $[1,7,8]$. In 2004, Shah et al. proposed a classification of SRLV strains based on sequence information of 2 genomic regions, the gag-pol $(1.8 \mathrm{~kb})$ and the pol $(1.2 \mathrm{~kb})$ region. The gag gene encodes for three proteins, being the matrix (MA), nucleocapsid 
(NC), and capsid (CA) proteins, and the pol gene encodes for enzymatic proteins including the reverse transcriptase (RT) [9]. Sequencing of both regions resulted in an initial classification of SRLVs into four genotypes from $\mathrm{A}$ to $\mathrm{D}$ and further subdivision of genotype $\mathrm{A}$ and $\mathrm{B}$ strains into $\mathrm{A} 1$ to $\mathrm{A} 7$ and $\mathrm{B} 1$ to $\mathrm{B} 2$ subtypes [7]. Genotypes A and B strains were referred to as MVV-like and CAEV-like, respectively, and are the most predominant strains around the world. Group $C$ strains were identified in Norwegian sheep and goats while genotype D strains comprised only a few strains from sheep and goats located in Switzerland and Spain $[7,10]$.

Since this initial classification, many other strains have been characterized and added to the phylogenetic tree, but often based on much shorter genomic fragments than those proposed by Shah et al. [7,11]. This leads to a current SRLV phylogeny containing 5 genotypes and 28 subtypes. The high number of subtypes reflects the high genetic heterogeneity between SRLV strains, which in turn impairs the performance of diagnostic tests $[12,13]$.

In Belgium, a recent nationwide seroprevalence study confirmed the presence of SRLV in $13 \%$ and $17 \%$ of sheep and goat farms, respectively [14]. Therefore, we decided to perform a genetic characterization of SRLV strains circulating in the Belgian sheep and goat population, based on the genomic fragments proposed by Shah et al. We also carried out a critical evaluation of the current SRLV classification and propose to apply more rigorous sequencing standards to ensure a correct classification of current and future SRLV subtypes.

\section{Results}

\subsection{Analysis of the Current SRLV Phylogeny}

Table 1 provides an overview of the fragment lengths and target regions that have been used to add new strains and identify new subtypes to the current SRLV phylogeny.

The basis of the current classification of SRLV strains was proposed in 2004 by Shah et al. using the genetic sequence of a $1.8 \mathrm{~kb}$ fragment in the gag-pol region, a $1.2 \mathrm{~kb}$ fragment in the pol region, and a smaller fragment ( $279 \mathrm{bp}$ ) within the reverse transcriptase (RT) region. Subtypes A1 to A5 were classified based on sequence information in these three regions, just as subtypes B1, B2, and genotype C. Subtypes A6, A7, and genotype D were classified on the basis of the nucleotide sequence of only one of these regions.

Later on, more strains were added to the phylogeny by others, but often based on the sequence of only a smaller part of one of the fragments initially proposed by Shah et al. This was the case for A8, A9, A10, A11, A18, B4, and genotype E which includes subtypes E1 and E2. Other studies also used smaller fragments but confirmed their classification in multiple regions. The identification of A12 and A13 was, for example, supported by the classification of 3 small fragments within the env and gag genes.

This overview clearly shows that different fragments and regions have been used over time to characterize new strains. Since the classification of Shah et al., one new genotype and 17 new subtypes have been added to the current phylogeny but mostly based on fewer same sequence information as proposed in the initial classification. This raises the question whether the current classification with all the published subtypes would still hold when those strains would have been added to the phylogeny based on the full fragments proposed by Shah et al. Furthermore, different publications used different programs and methods to obtain their phylogenetic trees, what could further impact and complicate the comparison between studies. 
Table 1. Overview of the small ruminant lentivirus (SRLV) subtypes that have been characterized and published since 2004. RT, reverse transcriptase fragment; CA, capsid; MA, matrix; SU, surface fragments; env, envelope gene.

\begin{tabular}{|c|c|c|c|c|c|}
\hline Subtypes & $\begin{array}{l}\text { Genomic Regions Used } \\
\text { for the Classification }\end{array}$ & Year & $\begin{array}{l}\text { Species in Which the } \\
\text { Subtype Was Detected }\end{array}$ & Country of Origin & References \\
\hline A1 & \multirow{5}{*}{$\begin{array}{c}\text { gag-pol }(1.8 \mathrm{~kb}) \\
\text { pol }(1.2 \mathrm{~kb}) \\
\text { RT (279 bp) }\end{array}$} & 2004 & Sheep & Iceland & [7] \\
\hline A2 & & 2004 & Sheep & North America & [7] \\
\hline A3 & & 2004 & Sheep and goats & Switzerland & [7] \\
\hline A4 & & 2004 & Sheep and goats & Switzerland & [7] \\
\hline A5 & & 2004 & Goats & Switzerland & [7] \\
\hline A6 & RT (279 bp) & 2004 & Sheep and goats & Southern France & [7] \\
\hline A7 & pol $(1.2 \mathrm{~kb})$ & 2004 & Goats & Switzerland & [7] \\
\hline $\mathrm{A} 8$ & $g a g(684 \mathrm{bp})$ & 2007 & Goats & Italy & [15] \\
\hline A9 & gag (684 bp) & 2007 & Sheep and goats & Italy & [15] \\
\hline A10 & pol (353 bp) & 2010 & Goats & Italy & [16] \\
\hline A11 & gag-pol (640 bp) & 2011 & Sheep and goats & Italy & [17] \\
\hline A12 & \multirow{2}{*}{$\begin{array}{l}\text { CA (467 bp) } \\
\text { MA(327 bp) } \\
\text { SU (394 bp) }\end{array}$} & \multirow{2}{*}{2012} & Sheep and goats & Poland & [12] \\
\hline A13 & & & Sheep and goats & Poland & [12] \\
\hline A14 & \multirow{2}{*}{$\begin{array}{c}\text { gag-pol (1471 bp) } \\
\text { pol (1025 bp) }\end{array}$} & 2013 & Goats & Slovenia & [18] \\
\hline A15 & & 2013 & Sheep & Slovenia & [18] \\
\hline A16 & \multirow{2}{*}{$\begin{array}{l}\text { CA (467 bp) } \\
\text { env (344 bp) }\end{array}$} & 2018 & Goats & Poland & [11] \\
\hline A17 & & 2018 & Goats & Poland & [11] \\
\hline A18* & gag (576 bp) & 2019 & Sheep & Poland & [19] \\
\hline A18* & \multirow{2}{*}{$\begin{array}{c}\text { Full genome } \\
\text { partial gag gene }\end{array}$} & 2019 & Goat & Italy & [20] \\
\hline A19 & & 2019 & Sheep & Italy & [20] \\
\hline B1 & \multirow{2}{*}{$\begin{array}{c}\text { gag-pol (1.8 kb) } \\
\text { pol (1.2 kb) } \\
\text { RT (279 bp) }\end{array}$} & 2004 & Sheep and goats & U.S & [7] \\
\hline B2 & & 2004 & Sheep & Switzerland & [7] \\
\hline B3 & $\begin{array}{c}\text { gag-pol (1320 bp) } \\
\text { pol (3201 bp) } \\
\text { env (2814 bp) }\end{array}$ & 2011 & Sheep and goats & Italy & [21] \\
\hline B4 & gag (1187 bp) & 2013 & goats & Canada & [22] \\
\hline $\mathrm{C}$ & $\begin{array}{c}\text { gag-pol }(1.8 \mathrm{~kb}) \\
\text { pol }(1.2 \mathrm{~kb}) \\
\text { RT (279 bp) }\end{array}$ & 2004 & Sheep and goats & Norway & [7] \\
\hline $\mathrm{D}$ & pol $(1.2 \mathrm{~kb})$ & 2004 & Sheep and goats & Switzerland & [7] \\
\hline E1 & gag (525 bp) & 2010 & Goats & Italy & [23] \\
\hline E2 & gag (525 bp) & 2010 & Goats & Italy & [23] \\
\hline
\end{tabular}

* Two subtypes A18 were published by two independent research groups within the same month. Olech et al. were the first group to published subtype A18.

\subsection{Phylogeny of Belgian SRLV Strains in the Gag-Pol Region}

Proviral DNA of 14 SRLV strains from sheep and 7 SRLV strains from goats originating from different Belgian provinces were successfully sequenced in the gag-pol region (Table 2), while no sequences were obtained in this region for the 1 SRLV strain present in sheep and 3 strains present in goats.

After alignment with sequences available in GeneBank, a phylogenetic analysis was performed using the neighbor-joining method on the consensus fragment of $1516 \mathrm{bp}$. Our analysis showed that 13 out of 14 sequenced Belgian SRLV strains from sheep belonged to subtype A1 (Figure 1; Table 2). A mean nucleotide diversity of $15.7 \%$ was identified between the reference strain KV1514 (A1) and the group of sheep strains associated to A1. Interestingly, one sheep strain (H.4.2) clustered within subtype B1 and is thus indicative for the occurrence of natural SRLV cross-species transmission from goats to sheep. This B1 strain showed a nucleotide distance of $10.9 \%$ to the reference B1 Cork strain. 
Table 2. List of samples characterized in the present analysis. For each samples, the species, the characteristics of the farm they are originated from, the provinces, the $\mathrm{Ct}$ values and the subtypes obtained in the gag-pol and pol fragments are mentioned. Accession numbers are shown between brackets.

\begin{tabular}{|c|c|c|c|c|c|c|c|c|c|c|}
\hline $\begin{array}{c}\text { Animal } \\
\text { Identification }\end{array}$ & Species & $\begin{array}{l}\text { Type of } \\
\text { Farm } \\
\text { Activity }\end{array}$ & $\begin{array}{c}\text { Mixed } \\
\text { Herds with } \\
\text { Sheep and } \\
\text { Goats }\end{array}$ & $\begin{array}{l}\text { Farms Size } \\
\text { (Number of } \\
\text { Animals) }\end{array}$ & Province (Belgium) & $\begin{array}{l}\text { Ct Values } \\
\text { Obtained in } \\
\text { qPCR }\end{array}$ & Gag-Pol Subtype & $\begin{array}{l}\text { Genetic Distances to } \\
\text { the Closest Reference } \\
\text { Strains } \\
\text { (MVV1514/CAEV } \\
\text { Cork) for the Gag-Pol } \\
\text { Fragment * }\end{array}$ & Pol Subtype & $\begin{array}{l}\text { Genetic Distances to } \\
\text { the Closest Reference } \\
\text { Strains } \\
\text { (MVV1514/CAEV } \\
\text { Cork) for the Pol } \\
\text { Fragment * }\end{array}$ \\
\hline A.3.4 & Sheep & Hobby & Yes & 7 & Antwerp & $\mathrm{Neg}$ & A1 (MN784764) & $17.02 \%$ & A1 (MN784784) & $17.63 \%$ \\
\hline H.4.2 & Sheep & Hobby & No & 17 & Hainaut & Neg & B1 (MN784761) & $10.47 \%$ & N.O & \\
\hline LB.1.6 & Sheep & Professional & No & 65 & Limburg & 32.91 & A1 (MN784760) & $16.10 \%$ & A1 (MN784782) & $16.75 \%$ \\
\hline LK.3.3 & Sheep & Hobby & No & 7 & Liege & 33.25 & A1 (MN784758) & $15.95 \%$ & A1 (MN784779) & $17.83 \%$ \\
\hline LK.5.4 & Sheep & Hobby & No & 23 & Liege & 32.29 & A1 (MN784757) & $15.74 \%$ & A1 (MN784778) & $18.12 \%$ \\
\hline LK.6.3 & Sheep & Professional & No & 150 & Liege & 34.14 & A1 (MN784756) & $14.81 \%$ & A1 (MN784777) & $17.43 \%$ \\
\hline LX.2.1 & Sheep & Professional & No & 226 & Luxembourg & 29.1 & A1 (MN784755) & $15.17 \%$ & A1 (MN784776) & $18.41 \%$ \\
\hline OV.1.7 & Sheep & Hobby & No & 15 & East Flanders & 35.13 & A1 (MN784754) & $15.10 \%$ & A1 (MN784775) & $17.43 \%$ \\
\hline OV.13.1 & Sheep & Hobby & No & 10 & East Flanders & 33.08 & A1 (MN784752) & $14.60 \%$ & A1 (MN784774) & $18.51 \%$ \\
\hline OV.20.1 & Sheep & Hobby & No & 15 & East Flanders & 34.1 & A1 (MN784751) & $15.67 \%$ & A1 (MN784773) & $16.85 \%$ \\
\hline VB.1.2 & Sheep & Hobby & No & 12 & Flemish Brabant & 36.82 & A1 (MN784750) & $15.53 \%$ & A1 (MN784771) & $18.41 \%$ \\
\hline VB.3.1 & Sheep & Hobby & Yes & 7 & Flemish Brabant & Neg & N.O ${ }^{a}$ & & N.O & \\
\hline VB.7.7 & Sheep & Hobby & No info & 7 & Flemish Brabant & 32.35 & A1 (MN784748) & $16.24 \%$ & A1 (MN784772) & $17.43 \%$ \\
\hline WV.4.3 & Sheep & Hobby & No & 10 & West Flanders & 35.28 & A1 (MN784746) & $16.38 \%$ & A1 (MN784767) & $16.94 \%$ \\
\hline WV.14.5 & Sheep & Professional & No info & 200 & West Flanders & 35.06 & A1 (MN784744) & $14.46 \%$ & A1 (MN784769) & $17.43 \%$ \\
\hline H.1.6 & Goat & Hobby & Yes & 10 & Hainaut & 40 & B1 (MN784763) & $11.25 \%$ & N.O & \\
\hline H.2.6 & Goat & Professional & No & 100 & Hainaut & 36.78 & B1 (MN784762) & $12.39 \%$ & B1 (MN784783) & $13.22 \%$ \\
\hline LB.2.3 & Goat & Hobby & No & 3 & Limburg & 32.55 & B1 (MN784759) & $12.25 \%$ & B5 (MN784781) & $13.12 \%$ \\
\hline LK.3.1 & Goat & Hobby & No & 4 & Liege & 40 & N.O & & A1 (MN784780) & $18.90 \%$ \\
\hline OV.4.5 & Goat & Hobby & Yes & 15 & East Flanders & 38.97 & N.O & & N.O & \\
\hline OV.7.7 & Goat & Professional & No & 70 & East Flanders & 37.42 & B1 (MN784753) & $12.11 \%$ & N.O & \\
\hline VB.5.6 & Goat & Professional & Yes & 100 & Flemish Brabant & 36.65 & B1 (MN784749) & $12.89 \%$ & B5 (MN784770) & $13.22 \%$ \\
\hline WV.3.2 & Goat & Hobby & No & 3 & West Flanders & 36.7 & B1 (MN784747) & $12.54 \%$ & B1 (MN784768) & $13.12 \%$ \\
\hline WV.7.1 & Goat & Professional & Yes & 347 & West Flanders & 40 & N.O & & A1 (MN784766) & $18.22 \%$ \\
\hline WV.12.3 & Goat & Hobby & No & 10 & West Flanders & 34.12 & B1 (MN784745) & $11.32 \%$ & B1 (MN784765) & $12.63 \%$ \\
\hline
\end{tabular}

${ }^{\mathrm{a}}$ no sequence data obtained * genotype A strains were compared to MVV1514; genotype B strains were compared to CAEV Cork. 


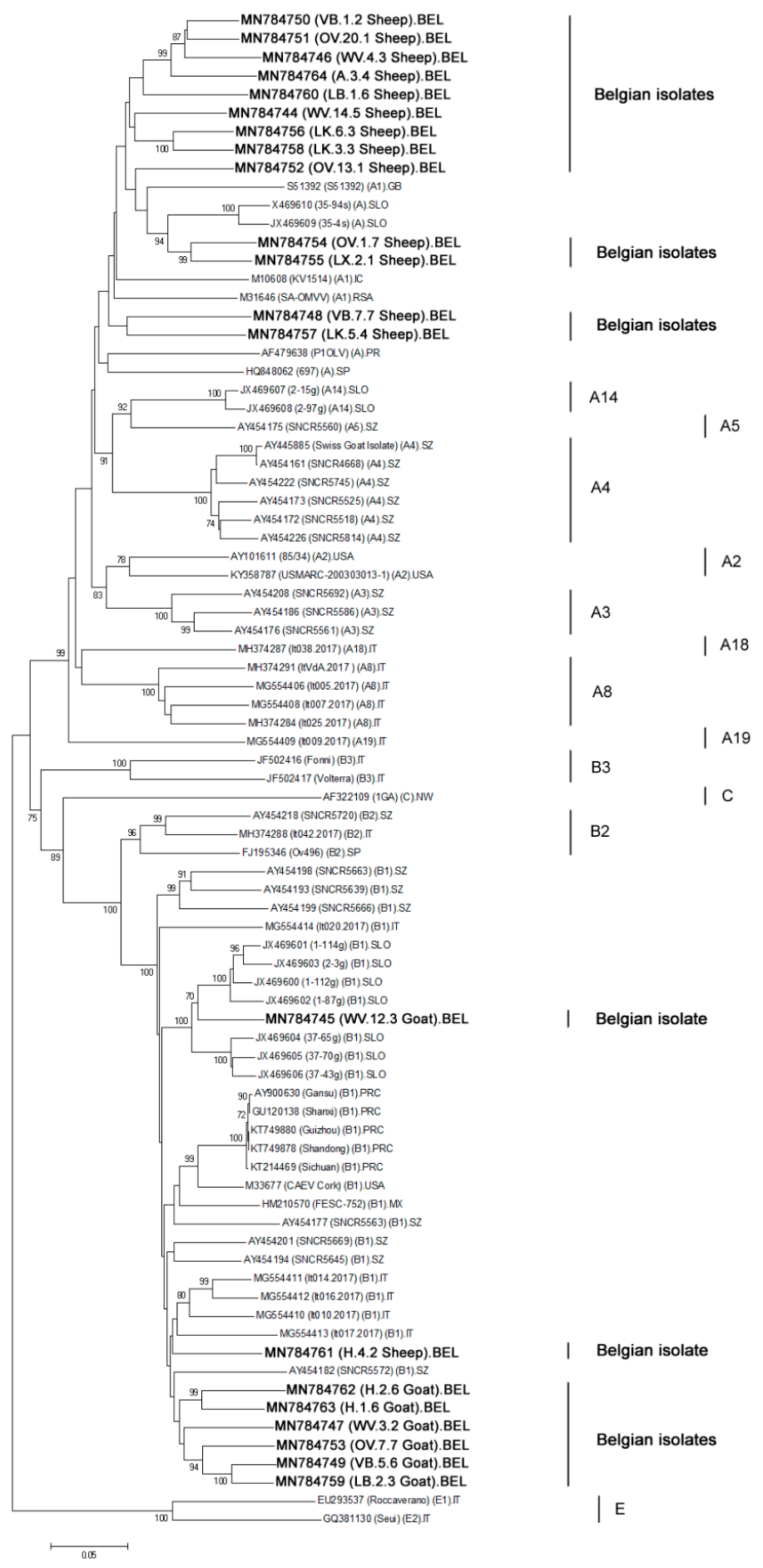

Figure 1. Phylogenetic tree was inferred by neighbor-joining using a $1516 \mathrm{bp}$ consensus fragment located in the gag-pol region $(1.8 \mathrm{~kb})$. Only bootstrap values $\geq 70$ are shown. All sequences are indicated by their GeneBank accession number and their names between brackets. For the Belgian isolates (21), indicated in bold, the provinces of origin are designated by their abbreviations: A: Antwerpen; $\mathrm{H}$ : Henegouwen; LB: Limburg; LK: Luik; LX: Luxemburg; OV: Oost-Vlaanderen; VB: Vlaams Brabant; WV: West-Vlaanderen. For the reference strains described in the literature, their subtype affiliations are named in parenthesis. For few strains, only the genotype affiliations were indicated. Country abbreviations are: BEL: Belgium; CA; Canada; FIN: Finland; GB: Great Britain; IC: Iceland; IT: Italy; MX: Mexico; NW: Norway; PR: Portugal; PRC: People's Republic of China; RSA: Republic of South Africa; SLO: Slovenia; SP: Spain; SZ: Switzerland; USA; United States of America. 
The 7 SRLV strains present in Belgian goats all showed to belong to subtype B1 in the gag-pol phylogeny (Figure 1; Table 2). They showed a nucleotide diversity of $12.5 \%$ with the Cork reference strain.

To evaluate the robustness of our analysis, we alternatively performed the phylogeny also using the maximum-likelihood and the Bayesian inference method, which resulted in the same classification of all strains (data not shown).

When analyzing the phylogeny based on the gag-pol region, it is furthermore interesting to observe that the Norwegian strain (1GA; AF322109), that was considered to be a genotype C strain by Shah [7], is classified as a genotype B strain in the gag-pol region. Subtype E1 and E2 strains could also be incorporated in the phylogenetic tree since they have been fully sequenced after their first classification. When considering the whole gag-pol region, they also remain classified as a separate genotype.

\subsection{Phylogeny of Belgian SRLV Strains in the Pol Region}

Amplicons of 13 sheep strains and 7 goat strains were successfully obtained in the pol region proposed by Shah et al. (Table 2). The phylogenetic analysis based on a $1068 \mathrm{bp}$ fragment showed that all SRLV strains from sheep clustered in subtype A1. Their mean diversity with the Icelandic reference strain KV1514 was 17.8\% (Figure 2). No sequence for the pol fragment could be obtained for the SRLV strain from sheep (H.4.2) that clustered with genotype B strains in the gag-pol region.

Five goat strains sequenced in the pol region belonged to genotype B (Figure 2) with a mean diversity of $12.9 \%$ compared to the reference Cork strain. These 5 Belgian goat isolates belonged to 2 different subtypes. Three strains (WV.12.3, WV.3.2, H.2.6) belonged to subtype B1 while two others (VB.5.6 and LB.2.3) formed a new separate cluster within genotype B (bootstrap value of 100\%). We propose to designate them as subtype B5 strains. These B5 strains show a genetic diversity of $13.22 \%$ and $13.12 \%$ with the B1 reference Cork strain. A recombination analysis with all strains present in the phylogeny was performed to verify if indications could be found that the B5 strains resulted from a recombination of already described sequences in the pol region. No event of recombination between known strains was identified in the pol region. It is important to notice that both B5 strains also clustered together in the gag-pol region but belonged to subtype B1 in that fragment (see higher). The finding that strains can cluster to different subtypes depending on the fragment that is considered was also observed for the current subtype A19 strain. This strain namely belongs to subtype A19 only in the gag-pol region while it clusters with subtype A1 strains in the pol region (Figure 2).

Two other SRLV strains from goats clustered within subtype A1, thereby providing evidence that SRLV transmission has occurred from sheep to goats as well. No sequences in the gag-pol region could be obtained for both strains (LK.3.1; WV.7.1) (Table 2).

The same classification was obtained in the pol region when we performed the maximum-likelihood and the Bayesian inference methods (data not shown).

Similar as mentioned already for the gag-pol analysis, subtypes E1 and E2 strains also form a separate genotype in the phylogenetic tree based on their sequences in the pol region. 

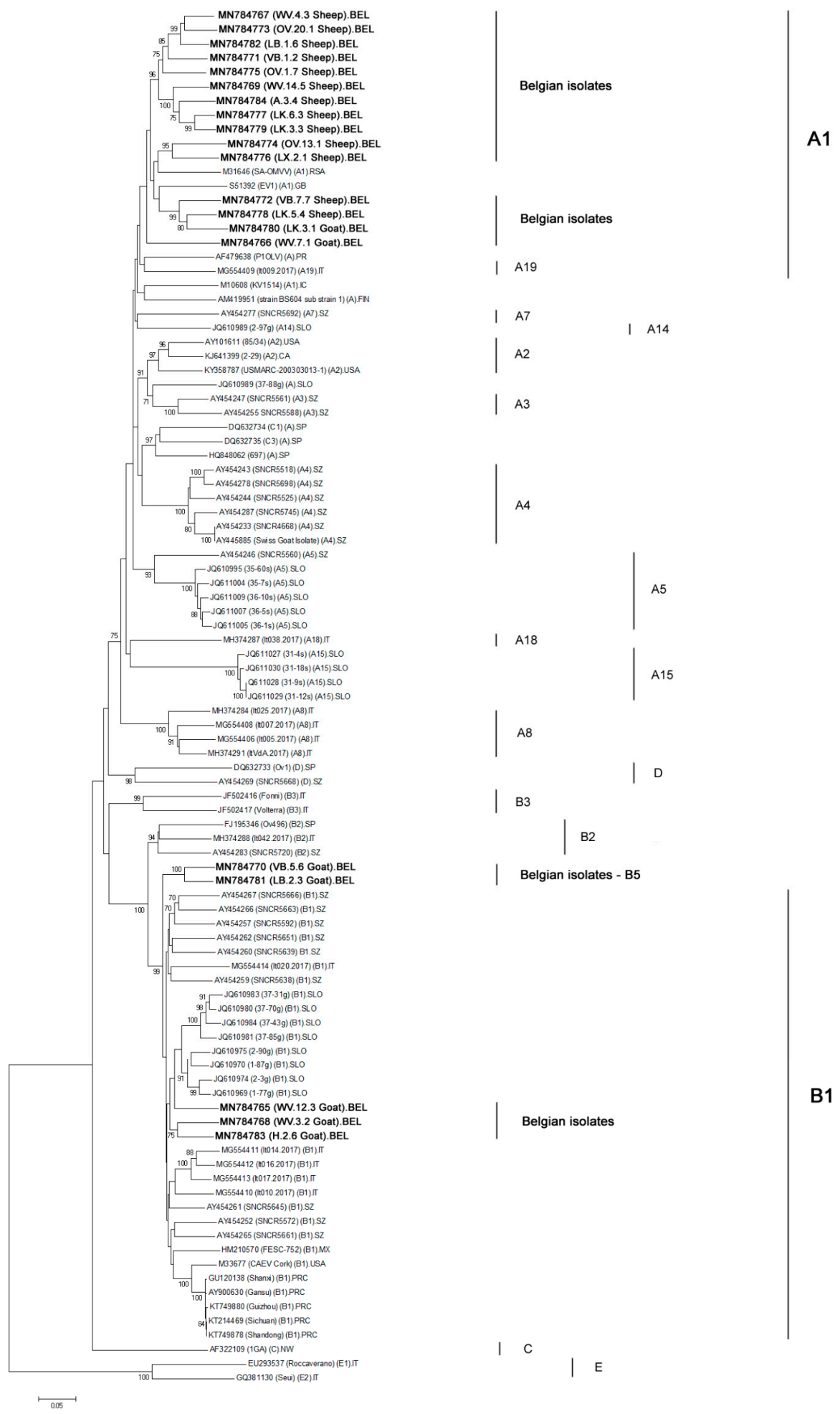

B1

Figure 2. Phylogenetic tree was inferred by neighbor-joining using a $1068 \mathrm{bp}$ consensus fragment located in the pol region $(1.2 \mathrm{~kb})$. Only bootstrap values $\geq 70$ are shown. All sequences are indicated by their GeneBank accession number and their names between brackets. For the Belgian isolates (20), indicated in bold, the provinces of origin are designated by their abbreviations: A: Antwerpen; $\mathrm{H}$ : Henegouwen; LB: Limburg; LK: Luik; LX: Luxemburg; OV: Oost-Vlaanderen; VB: Vlaams Brabant; WV: West-Vlaanderen. For the reference strains described in the literature, their subtype affiliations are named in parenthesis. For few strains, only the genotype affiliations were indicated. Country abbreviations are: BEL: Belgium; CA; Canada; FIN: Finland; GB: Great Britain; IC: Iceland; IT: Italy; MX: Mexico; NW: Norway; PR: Portugal; PRC: People's Republic of China; RSA: Republic of South Africa; SLO: Slovenia; SP: Spain; SZ: Switzerland; USA; United States of America. 


\section{Discussion}

The current SRLV phylogeny consisting of 5 genotypes, which are further divided in multiple subtypes, emphasizes the high genetic variation that exists among SRLV strains. This high genetic diversity between strains often poses challenges for countries that implemented SRLV eradication programs since none of the existing diagnostic tests are capable to detect all circulating strains [13,24]. Since a voluntary SRLV eradication program is running in Belgium, we wanted to get a better insight in the SRLV strains circulating in our country and decided to perform a genetic characterization of Belgian SRLV strains present in naturally infected sheep and goats.

The method described by Shah et al. [7] was used for this work, meaning that we attempted to sequence the gag-pol and pol regions. These have been described to be conserved genomic regions and are widely accepted for SRLV classification $[9,25]$. We successfully obtained sequences in at least one of both regions for 14 out of 15 SRLV strains from sheep and 7 out of 10 SRLV strains from goats. The fact that no sequences could be obtained for all strains or fragments is most probably due to the low proviral load in infected animals and the high genetic heterogeneity of SRLV strains. This heterogeneity has been reported to be higher among isolates from goats than from sheep and this seems to be reflected in our results [13]. Several mechanisms could explain the high genetic variations existing between SRLV. The first and most important is mostly attributed to the lack of proofreading driven by the reverse transcriptase enzyme (RT). The low fidelity of the enzyme during the reverse transcription stage is responsible for the introduction of new mutations in the SRLV genome (0.2-2 mutations per genome cycle). A second origin of genetic variation can be related to the APOBEC 3 enzyme, an intrinsic protein known to incorporate deleterious mutations into the viral genome by cytosine to uracil deamination. The excess of uracil in the reversely transcribed negative DNA strand can afterward lead to G-to-A mutations in the plus strand of proviral DNA. Along with this, macrophages, known to be SRLV target cells, are known to contain a higher amount of intracellular dUTPs. This excess of uracil can be incorporated into the DNA leading to more mutations in newly produced virions (reviewed in [13]). A third source of genetic evolution in lentiviruses that adds to their adaptability and genetic diversity is the occurrence of recombination between strains [26]. This mechanism allows viruses to combine genetic information which can lead to new emerging strains. Such events mostly occur when an animal is co-infected by two or more SRLV strains after cross or interspecies transmission [27]. The importation of infected animals and the lack of veterinary controls is also a another source of genetic heterogeneity within SRLV since new strains can be introduced into local herds [7].

Besides the expected finding of genotype A strains in sheep and genotype B strains in goats, we also found the presence of 2 genotype A1 strains in goats and one genotype B1 strain in a sheep. This indicates that cross species transmission from sheep to goats and vice versa has occurred. Cross species transmission of SRLV strains has been reported before $[8,27,28]$ and such transmission events probably occur via transmission of viral particles via the air when different species are in close contact or via feeding of contaminated milk from sheep to goat or vice versa $[8,26,29]$. Although animal WV.7.1 came from a farm where both sheep and goats were present, our available information does not allow to deduce whether the cross-species transmission has occurred at this farm, or that this strain entered the farm via the purchase of an animal infected with an A1 strain.

Remarkably, we could only obtain sequence information in either the gag-pol or the pol region using our methodology for these three strains indicative for cross species transmission. This suggests an even higher genetic divergence of these strains. This could be due to the fact that viruses are forced to adapt and evolve more rapidly when introduced into a new species, often resulting in the emergence of new diverging strains [26,30]. Some field studies have demonstrated such SRLV genetic adaptation induced by cross species transmission. Erhouma et al. showed that important genetic differences were present in the LTR region of proviral SRLV sequences after transmission from domestic goats to wild ibexes via natural contact. The gag gene, in turn, was better conserved [31]. Other studies also reported minor modifications in the genome after the passage of SRLV from sheep to goats and 
vice-versa $[7,8,28]$. In addition to this genetic adaptation to a new host, it could also be that these strains are the result of a recombination event that occurred in dually infected animals [26].

During analysis of the presented phylogenetic trees, it can be observed that the classification of strains to a specific subgroup can differ depending on the fragment that is analyzed. In the gag-pol phylogenetic tree, the strain belonging to subtype A19 is clearly separated from other genotype A subtypes [19], while in the pol tree, it clusters within subtype A1. A similar observation can be made when looking at the reference strains known to belong to genotype $C$. In the phylogeny based on the pol fragment, these indeed form a separate cluster, but when looking at the gag-pol sequence, they would be classified as genotype B strains. A similar observation was already made by Olech et al. who classified the genotype $C$ strains within genotype $B$ after sequence analysis of smaller fragments in the gag region. Kuhar et al., on the other hand, found the genotype $C$ strains to form separate groups in both phylogenetic trees based on longer gag-pol and pol sequences but not as long as seen in this study $[18,19]$. A similar observation is made for some of our Belgian strains. Two epidemiologically unrelated strains form a separate cluster within genotype B when looking at the phylogenetic tree based on the pol fragment. We propose to designate them as genotype B5 strains, seeing the high bootstrap value of their cluster and the high genetic distance they have with others genotype $B$ reference strains including B1, B2, and B3 (mean nucleotide distance of $17.9 \%$ in the gag-pol fragment and $18 \%$ in the pol fragment). In the gag-pol analysis, however, these strains cluster within the B1 subgroup. We therefore hypothesize that this strain finds its origin in a recombination between a B1 strain and an until hereto undescribed B5 strain upon co-infection of a goat. This seems more likely than a B1 strain accumulated by so many mutations in the pol genomic region.

Finally, analysis of the current phylogeny showed that many new genotypes and subtypes have been claimed based on shorter fragments than those proposed by Shah et al. It is not likely that the current phylogeny would stand if longer fragments would have been used. We therefore believe that more rigorous standards should be followed when adding strains to the phylogeny to ensure the correct classification of new emerging strains and suggest to use at least the gag-pol and the pol fragments proposed by Shah et al. Since phylogenetic analyses are a helpful tool to understand shortcomings of diagnostic tests, the availability of sufficiently long sequences will also be helpful to continuously improve diagnostic tests. Accessible sequence information for the gag-pol and pol region can help to develop and/or improve PCR tests for molecular SRLV detection. Furthermore, sequence information in the gag-pol region, covering epitopes of the capsid protein that are sometimes used as antigens in SRLV ELISAs [24], can also help to identify why some SRLV infected animals are not recognized by currently used ELISA tests and provide the necessary information to construct strain-specific ELISAs using strain-specific epitopes. Proof of concept studies on the use of peptides from SRLV SU5 and transmembrane proteins was already described for the detection of specific Spanish strains that were not detected by other ELISAs [32,33].

\section{Materials and Methods}

\subsection{Sample Selection}

Samples used in this study originated from a previous study carried out to determine the SRLV seroprevalence in Belgium (Table 2). Samples came from both small-scale hobbyist farms and professional farms that were not involved in the SRLV national control program. Independent of the farm size, 7 animals were sampled per farm. More details on the methodology and sample collection can be found in Michiels et al. [14] and details on the samples used in this study are presented in Table 2. Fifteen out of 87 sheep herds and 10 out of 76 goat herds were found to contain at least one SRLV infected animal. In the current study, we aimed to characterize the SRLV strain present at each seropositive sheep and goat farm. For every positive farm, we selected the sample that showed to contain the highest amount of SRLV proviral DNA, i.e., the animal that showed the lowest $\mathrm{Ct}$ value in previously described qPCR tests [24,34] (Table 2). If none of the animals in the farm tested positive 
in qPCR, but were positive in serology, the animal with most SRLV specific antibodies (based on S/P value) was selected. Animals that appeared to be infected by both a genotype A and B strain based on the qPCR analysis in the previous study were omitted from the analysis [24].

\subsection{DNA Extraction, PCR Amplification, and Sequencing}

Leucocyte pellets were obtained by treating $1.5 \mathrm{~mL}$ of EDTA blood with $8.5 \mathrm{~mL}$ of hemolysis buffer (16.6 $\mathrm{g} \mathrm{NH}_{4} \mathrm{Cl}, 2.0 \mathrm{~g} \mathrm{NaHCO}_{3}, 0.185 \mathrm{~g}$ diNa EDTA per $\mathrm{L}_{2} \mathrm{O}$; $\mathrm{pH}$ 7.4) [35]. After 20 min of incubation at room temperature, samples were centrifuged for $10 \mathrm{~min}$ at $3000 \times \mathrm{g}$ and the pellet was resuspended in $200 \mu \mathrm{L}$ of PBS. Genomic DNA, including proviral DNA, was then extracted from the leucocyte pellets using the QIAamp DNA Minikit (Qiagen, Hilden, Germany) following the manufacturer's instructions. Purified DNA was eluted in $100 \mu \mathrm{L}$ of elution buffer and stored at $-80^{\circ} \mathrm{C}$ until use.

We attempted to sequence all SRLV strains in the $1.8 \mathrm{~kb}$ gag-pol and the $1.2 \mathrm{~kb}$ pol region using the method of Shah et al. [7]. Different combinations of primers were used to obtain DNA fragments from the targeted regions. The $1.8 \mathrm{~kb}$ gag-pol region was amplified with the combination of P39-P37 primers, followed by nested PCRs using either P21-P41 or P40-P27. For few samples, P40-P37 was used instead of P40-P27. The amplification of the $1.2 \mathrm{~kb}$ pol region was done using the combination of P28 and P32 followed by a nested PCR using P29-P35 primers.

Amplification with P39-P37 and P28-P32 was done as follows: activation of the FastStart Taq DNA polymerase (Roche, Basel, Switzerland) at $95^{\circ} \mathrm{C}$ for $15 \mathrm{~min}, 45$ cycles of denaturation at $94^{\circ} \mathrm{C}$ for $30 \mathrm{~s}$, annealing at $55^{\circ} \mathrm{C}$ for $1 \mathrm{~min}$, and extension at $72{ }^{\circ} \mathrm{C}$ for $2 \mathrm{~min}$. For the nested PCRs, the following cycling conditions were used: $95^{\circ} \mathrm{C}$ for $15 \mathrm{~min}$, followed by 45 cycles of denaturation at $94{ }^{\circ} \mathrm{C}$ for $30 \mathrm{~s}$, annealing for $1 \mathrm{~min}$ at $51^{\circ} \mathrm{C}$ for P40-P27 and P40-P37, $53^{\circ} \mathrm{C}$ for P21-P41, and $57^{\circ} \mathrm{C}$ for P29-P35, followed by an extension step of $1 \mathrm{~min}$ at $72{ }^{\circ} \mathrm{C}$ for P21-P41 or $2 \mathrm{~min}$ for the other primer combination. The final reaction volume consisted on $25 \mu \mathrm{L}$ of $2 \times$ Fastart PCR Master, $2 \mu \mathrm{L}$ of each primer $(0.4 \mu \mathrm{M})$, $16 \mu \mathrm{L}$ of RNase-free water, and $5 \mu \mathrm{l}$ of DNA. Amplified fragments were visualized by electrophoresis on a $0.8 \%$ agarose gel containing $0.5 x$ GelRed Nucleic Acid Gel staining (Biotium, Fremont, CA, USA). Bands of expected sizes were excised and purified from gel using the QIAquick Gel extraction Kit (Qiagen, Hilden, Germany) following the manufacturer's instructions. Fragments were analyzed on a ABI 3130xl (Applied Biosystems, Carlsbad, CA, USA) and sequence analysis was done with BioEdit (version 7.2.5) software [36].

\subsection{Multiple Alignments and Phylogenetic Analysis}

All obtained nucleotide sequences in both genomic regions were aligned with the reference strains obtained from GeneBank using ClustalW included within the software MEGA 7.0 [37]. After alignment, sequences were trimmed and final fragments of $1516 \mathrm{bp}$ and $1068 \mathrm{bp}$ for the gag-pol and pol regions, respectively, were used for the final phylogenetic analysis. The new Belgian sequences reported in this study are available in the GeneBank under accession numbers MN784744 to MN784764 for the gag-pol sequences and MN784765 to MN784784 for the pol sequences. The phylogenetic reconstructions were performed using the neighbor-joining method implemented in MEGA 7.0 with the maximum likelihood substitution model and a statistical confidence of 1000 replicates [38]. Branches with bootstrap values of $70 \%$ or higher were considered to form a separate cluster. Genetic divergence was computed with MEGA 7.0 using the p-distance model and applying default settings. The tree topologies were also confirmed with the maximum-likelihood and the Bayesian inference methods. The maximum likelihood analysis was performed in MEGA 7.0 with the Tamura-Nei model (bootstrap values of 1000 replications) and the Bayesian analysis was externally performed using MrBayes (version 3.2.2) implemented in CIPRES Science Gateway $[39,40]$.

\subsection{Recombination Analysis}

The RDP4 software (RDP, GeneConv, Bootscan, MaxChi, Chimera, SiScan, and 3Seq) was used to perform a recombination analysis in the gag-pol and pol regions of the SRLV sequences, respectively. 
Seven algorithms implemented in the software analyzed whether the Belgian strains that were added to the phylogeny could be the result of a recombination between any of the reference strains that were used in this phylogenetic analysis. Default settings were applied and recombination events were considered as significant if the $\mathrm{P}$ value was $<1.0 \mathrm{E}^{-6}$ in at least 4 algorithms $[41,42]$.

\section{Conclusions}

Our genetic characterization showed that most SRLVs strains circulating in naturally infected sheep and goats from Belgium belong to genotype A and B strains, respectively. We, however, also found clear indications for natural cross-species transmission between sheep and goats, with the presence of genotype B strains in sheep and genotype A strains in goats. The heterogeneity between SRLV strains circulating in Belgium was further emphasized by the presence of strains that do not cluster with already described strains and which we propose to be prototype B5 strains. In order to keep SRLV phylogeny as a relevant tool for the assessment of the heterogeneity between SRLV strains and to remain helpful in the development of appropriate diagnostic tests, it seems advisable that the standards proposed by Shah et al. on sequencing fragments and amplicons lengths should be more rigorously followed for addition of new strains to avoid a wild growth of new genotypes and subtypes based on short genomic sequences.

Author Contributions: Conceptualization, R.M. and N.D.R.; methodology, R.M., N.R.A. and N.D.R.; formal analysis, R.M. and N.D.R.; investigation, R.M. and N.D.R.; resources, N.D.R.; data curation, R.M. and N.D.R.; writing-Original draft preparation, R.M. and N.D.R.; writing-Review and editing, R.M. and N.D.R.; visualization, R.M.; supervision, N.D.R.; project administration, N.D.R.; funding acquisition, N.D.R. All authors have read and agreed to the published version of the manuscript.

Funding: This work was supported by the Federal Public Service of Health, Food Chain Safety and Environment (RF14/6289 SRLV-BEL) of Belgium.

Acknowledgments: The authors would like to thank the department of Transversal activities in Applied Genomics (Sciensano) for the sequencing.

Conflicts of Interest: None of the authors declares to have a conflict of interest that could influence or bias the content of the paper.

\section{References}

1. Leroux, C.; Cruz, J.; Mornex, J. Srlvs: A Genetic Continuum of Lentiviral Species in Sheep and Goats with Cumulative Evidence of Cross Species Transmission. Curr. HIV Res. 2010, 8, 94-100. [PubMed]

2. Blacklaws, B.A. Small Ruminant Lentiviruses: Immunopathogenesis of Visna-Maedi and Caprine Arthritis and Encephalitis Virus. Comp. Immunol. Microbiol. Infect. Dis. 2012, 35, 259-269. [CrossRef] [PubMed]

3. Glaria, I.; Reina, R.; Ramirez, H.; de Andres, X.; Crespo, H.; Jauregui, P.; Salazar, E.; Lujan, L.; Perez, M.M.; Benavides, J.; et al. Visna/Maedi Virus Genetic Characterization and Serological Diagnosis of Infection in Sheep from a Neurological Outbreak. Vet. Microbiol. 2012, 155, 137-146. [CrossRef]

4. Minguijon, E.; Reina, R.; Perez, M.; Polledo, L.; Villoria, M.; Ramirez, H.; Leginagoikoa, I.; Badiola, J.J.; Garcia-Marin, J.F.; de Andres, D.; et al. Small Ruminant Lentivirus Infections and Diseases. Vet. Microbiol. 2015, 181, 75-89. [CrossRef]

5. Blacklaws, B.A.; Berriatua, E.; Torsteinsdottir, S.; Watt, N.J.; de Andres, D.; Klein, D.; Harkiss, G.D. Transmission of Small Ruminant Lentiviruses. Vet. Microbiol. 2004, 101, 199-208. [CrossRef]

6. Alvarez, V.; Arranz, J.; Daltabuit-Test, M.; Leginagoikoa, I.; Juste, R.A.; Amorena, B.; de Andres, D.; Lujan, L.L.; Badiola, J.J.; Berriatua, E. Relative Contribution of Colostrum from Maedi-Visna Virus (Mvv) Infected Ewes to Mvv-Seroprevalence in Lambs. Res. Vet. Sci. 2005, 78, 237-243. [CrossRef]

7. Shah, C.; Böni, J.; Huder, J.B.; Vogt, H.R.; Mühlherr, J.; Zanoni, R.; Miserez, R.; Lutz, H.; Schüpbach, J. Phylogenetic Analysis and Reclassification of Caprine and Ovine Lentiviruses Based on 104 New Isolates: Evidence for Regular Sheep-to-Goat Transmission and Worldwide Propagation through Livestock Trade. Virology 2004, 319, 12-26. [CrossRef]

8. Pisoni, G.; Quasso, A.; Moroni, P. Phylogenetic Analysis of Small-Ruminant Lentivirus Subtype B1 in Mixed Flocks: Evidence for Natural Transmission from Goats to Sheep. Virology 2005, 339, 147-152. [CrossRef] 
9. Pepin, M.; Vitu, C.; Russo, P.; Mornex, J.F.; Peterhans, E. Maedi-Visna Virus Infection in Sheep: A Review. Vet. Res. 1998, 29, 341-367. [PubMed]

10. Gjerset, B.; Rimstad, E.; Teige, J.; Soetaert, K.; Jonassen, C.M. Impact of Natural Sheep-Goat Transmission on Detection and Control of Small Ruminant Lentivirus Group C Infections. Vet. Microbiol. 2009, 135, 231-238. [CrossRef] [PubMed]

11. Olech, M.; Valas, S.; Kuzmak, J. Epidemiological Survey in Single-Species Flocks from Poland Reveals Expanded Genetic and Antigenic Diversity of Small Ruminant Lentiviruses. PLoS ONE 2018, 13, e0193892. [CrossRef] [PubMed]

12. Olech, M.; Rachid, A.; Croise, B.; Kuzmak, J.; Valas, S. Genetic and Antigenic Characterization of Small Ruminant Lentiviruses Circulating in Poland. Virus Res. 2012, 163, 528-536. [CrossRef] [PubMed]

13. Ramirez, H.; Reina, R.; Amorena, B.; de Andres, D.; Martinez, H.A. Small Ruminant Lentiviruses: Genetic Variability, Tropism and Diagnosis. Viruses 2013, 5, 1175-1207. [CrossRef] [PubMed]

14. Michiels, R.; Mael, E.V.; Quinet, C.; Welby, S.; Cay, B.; Regge, N.D. Seroprevalence and Risk Factors Related to Small Ruminant Lentivirus Infections in Belgian Sheep and Goats. Prev. Vet. Med. 2018, 151, 13-20. [CrossRef]

15. Grego, E.; Bertolotti, L.; Quasso, A.; Profiti, M.; Lacerenza, D.; Muz, D.; Rosati, S. Genetic Characterization of Small Ruminant Lentivirus in Italian Mixed Flocks: Evidence for a Novel Genotype Circulating in a Local Goat Population. J. Gen. Virol. 2007, 88, 3423-3427. [CrossRef]

16. Pisoni, G.; Bertoni, G.; Manarolla, G.; Vogt, H.R.; Scaccabarozzi, L.; Locatelli, C.; Moroni, P. Genetic Analysis of Small Ruminant Lentiviruses Following Lactogenic Transmission. Virology 2010, 407, 91-99. [CrossRef]

17. Giammarioli, M.; Bazzucchi, M.; Puggioni, G.; Brajon, G.; Giudici, S.D.; Taccori, F.; Feliziani, F.; de Mia, G.M. Phylogenetic Analysis of Small Ruminant Lentivirus (Srlv) in Italian Flocks Reveals the Existence of Novel Genetic Subtypes. Virus Genes 2011, 43, 380-384. [CrossRef]

18. Kuhar, U.; Barlic-Maganja, D.; Grom, J. Phylogenetic Analysis of Small Ruminant Lentiviruses Detected in Slovenia. Vet. Microbiol. 2013, 162, 201-206. [CrossRef]

19. Olech, M.; Murawski, M.; Kuzmak, J. Molecular Analysis of Small-Ruminant Lentiviruses in Polish Flocks Reveals the Existence of a Novel Subtype in Sheep. Arch. Virol. 2019, 164, 1193-1198. [CrossRef]

20. Colitti, B.; Coradduzza, E.; Puggioni, G.; Capucchio, M.T.; Reina, R.; Bertolotti, L.; Rosati, S. A New Approach for Small Ruminant Lentivirus Full Genome Characterization Revealed the Circulation of Divergent Strains. PLos ONE 2019, 14, e0212585. [CrossRef]

21. Bertolotti, L.; Mazzei, M.; Puggioni, G.; Carrozza, M.L.; Giudici, S.D.; Muz, D.; Juganaru, M.; Patta, C.; Tolari, F.; Rosati, S. Characterization of New Small Ruminant Lentivirus Subtype B3 Suggests Animal Trade within the Mediterranean Basin. J. Gen. Virol. 2011, 92, 1923-1929. [CrossRef] [PubMed]

22. Santry, L.A.; de Jong, J.; Gold, A.C.; Walsh, S.R.; Menzies, P.I.; Wootton, S.K. Genetic Characterization of Small Ruminant Lentiviruses Circulating in Naturally Infected Sheep and Goats in Ontario, Canada. Virus Res. 2013, 175, 30-44. [CrossRef] [PubMed]

23. Reina, R.; Bertolotti, L.; Giudici, S.D.; Puggioni, G.; Ponti, N.; Profiti, M.; Patta, C.; Rosati, S. Small Ruminant Lentivirus Genotype E Is Widespread in Sarda Goat. Vet. Microbiol. 2010, 144, 24-31. [CrossRef] [PubMed]

24. Michiels, R.; van Mael, E.; Quinet, C.; Adjadj, N.R.; Cay, A.B.; de Regge, N. Comparative Analysis of Different Serological and Molecular Tests for the Detection of Small Ruminant Lentiviruses (Srlvs) in Belgian Sheep and Goats. Viruses 2018, 10, 696. [CrossRef] [PubMed]

25. Zanoni, R.; Pauli, U.; Peterhans, E. Caprine Arthritis-Encephalitis (Cae) and Maedi-Visna Viruses Detected by Polymerase Chain Reaction (Pcr). Vet. Microbiol. 1990, 23, 329-335. [CrossRef]

26. Minardi da Cruz, J.C.; Singh, D.K.; Lamara, A.; Chebloune, Y. Small Ruminant Lentiviruses (Srlvs) Break the Species Barrier to Acquire New Host Range. Viruses 2013, 5, 1867-1884. [CrossRef]

27. Pisoni, G.; Bertoni, G.; Puricelli, M.; Maccalli, M.; Moroni, P. Demonstration of Coinfection with and Recombination by Caprine Arthritis-Encephalitis Virus and Maedi-Visna Virus in Naturally Infected Goats. J. Virol. 2007, 81, 4948-4955. [CrossRef]

28. Shah, C.; Huder, J.B.; Boni, J.; Schonmann, M.; Muhlherr, J.; Lutz, H.; Schupbach, J. Direct Evidence for Natural Transmission of Small-Ruminant Lentiviruses of Subtype A4 from Goats to Sheep and Vice Versa. J. Virol. 2004, 78, 7518-7522. [CrossRef] 
29. Souza, T.S.; Pinheiro, R.R.; Costa, J.N.; Lima, C.C.; Andrioli, A.; Azevedo, D.A.; Santos, V.W.; Araujo, J.F.; Sousa, A.L.; Pinheiro, D.N.; et al. Interspecific Transmission of Small Ruminant Lentiviruses from Goats to Sheep. Braz. J. Microbiol. 2015, 46, 867-874. [CrossRef]

30. Courgnaud, V.; Saurin, W.; Villinger, F.; Sonigo, P. Different Evolution of Simian Immunodeficiency Virus in a Natural Host and a New Host. Virology 1998, 247, 41-50. [CrossRef]

31. Erhouma, E.; Guiguen, F.; Chebloune, Y.; Gauthier, D.; Lakhal, L.M.; Greenland, T.; Mornex, J.F.; Leroux, C.; Alogninouwa, T. Small Ruminant Lentivirus Proviral Sequences from Wild Ibexes in Contact with Domestic Goats. J. Gen. Virol. 2008, 89, 1478-1484. [CrossRef] [PubMed]

32. de Andres, X.; Ramirez, H.; Bertolotti, L.; Roman, B.S.; Glaria, I.; Crespo, H.; Jauregui, P.; Minguijon, E.; Juste, R.; Leginagoikoa, I.; et al. An Insight into a Combination of Elisa Strategies to Diagnose Small Ruminant Lentivirus Infections. Vet. Immunol. Immunopathol. 2013, 152, 277-288. [CrossRef] [PubMed]

33. Sanjose, L.; Pinczowski, P.; Crespo, H.; Perez, M.; Glaria, I.; Gimeno, M.; de Andres, D.; Amorena, B.; Lujan, L.; Reina, R. Diagnosing Infection with Small Ruminant Lentiviruses of Genotypes a and B by Combining Synthetic Peptides in Elisa. Vet. J. 2015, 204, 88-93. [CrossRef] [PubMed]

34. De Regge, N.; Cay, B. Development, Validation and Evaluation of Added Diagnostic Value of a Q(Rt)-Pcr for the Detection of Genotype a Strains of Small Ruminant Lentiviruses. J. Virol. Methods 2013, 194, 250-257. [CrossRef]

35. Mignon, B.; Waxweiler, S.; Thiry, E.; Boulanger, D.; Dubuisson, J.; Pastoret, P.P. Epidemiological Evaluation of a Monoclonal Elisa Detecting Bovine Viral Diarrhoea Pestivirus Antigens in Field Blood Samples of Persistently Infected Cattle. J. Virol. Methods 1992, 40, 85-93. [CrossRef]

36. Hall, T.A. Bioedit: A User-Friendly Biological Sequence Alignment Editor and Analysis Program for Windows 95/98/Nt. Nucleic. Acids Symp. Ser. 1999, 41, 95-98.

37. Thompson, J.D.; Higgins, D.G.; Gibson, T.J. Clustal W: Improving the Sensitivity of Progressive Multiple Sequence Alignment through Sequence Weighting, Position-Specific Gap Penalties and Weight Matrix Choice. Nucleic. Acids Res. 1994, 22, 4673-4680. [CrossRef]

38. Tamura, K.; Nei, M.; Kumar, S. Prospects for Inferring Very Large Phylogenies by Using the Neighbor-Joining Method. Proc. Natl. Acad. Sci. USA 2004, 101, 11030-11035. [CrossRef]

39. Miller, M.A.; Pfeiffer, W.; Schwartz, T. Creating the Cipres Science Gateway for Inference of Large Phylogenetic Trees. In Proceedings of the Gateway Computing Environments Workshop (GCE) (2010), New Orleans, LA, USA, 14 November 2010; pp. 1-8.

40. Kumar, S.; Stecher, G.; Tamura, K. Mega7: Molecular Evolutionary Genetics Analysis Version 7.0 for Bigger Datasets. Mol. Biol. Evol. 2015, 33, 1870-1874. [CrossRef]

41. Martin, D.P.; Murrell, B.; Golden, M.; Khoosal, A.; Muhire, B. Rdp4: Detection and Analysis of Recombination Patterns in Virus Genomes. Virus Evol. 2015, 1, vev003. [CrossRef] [PubMed]

42. Fei, D.; Guo, Y.; Fan, Q.; Wang, H.; Wu, J.; Li, M.; Ma, M. Phylogenetic and Recombination Analyses of Two Deformed Wing Virus Strains from Different Honeybee Species in China. PeerJ 2019, 7, e7214. [CrossRef] [PubMed]

(C) 2020 by the authors. Licensee MDPI, Basel, Switzerland. This article is an open access article distributed under the terms and conditions of the Creative Commons Attribution (CC BY) license (http://creativecommons.org/licenses/by/4.0/). 